\title{
Saberes evidenciados nos documentos oficiais de âmbito federal para o currículo de cursos de licenciatura em Matemática
}

\author{
Armando Traldi $\mathrm{Jr}^{1}$ \\ Reginaldo Guilhermino Cabral Libório ${ }^{2}$
}

\begin{abstract}
RESUMO
O objetivo de pesquisa apresentado neste artigo é compreender os saberes explicitados nos documentos oficiais que normatizam a formação inicial do professor de matemática. $\mathrm{O}$ estudo desenvolvido é de natureza qualitativa e do tipo documental. A partir deste estudo é possível afirmar que os "saberes a ensinar" e os "saberes para ensinar" estiveram presentes nas normativas oficiais para a configuração curricular dos cursos de licenciatura em Matemática desde a implantação dos primeiros cursos. Porém, a ênfase estava prioritamente nos "saberes a ensinar", pois a inserção da "matemática escolar" nos documentos oficiais ocorreu a partir de 1961, entretanto, ainda, sem considerar o contexto real da escola. É no documento publicado em 2002 que é explicitada a real necessidade da articulação entre estes saberes. Neste sentido, pode-se afirmar a necessidade de se compreender um novo saber que é o amálgama entre estes saberes.
\end{abstract}

PALAVRAS-CHAVE: Currículo prescrito. Licenciatura em Matemática. Saber a ensinar. Saber para ensinar.

Knowledge got that in official federal documents for the curriculum of licensing courses in Mathematics

\footnotetext{
${ }^{1}$ Doutor em Educação Matemática. Professor titular do Departamento de Matemática do IFSP. https://orcid.org/00000001-8337-3977.traldijr@gmail.com.

${ }^{2}$ Mestre em Ensino de Ciências e Matemática - IFSP. Doutorando em Ensino e História das Ciências e da Matemática (UFABC). https://orcid.org/0000-0003-0929-5397.rgliborio@gmail.com.
} 


\begin{abstract}
The research objective presented in this article is to understand the knowledge explained in the official documents, which standardize the initial formation of the mathematics teacher. The study developed is of a qualitative nature of the documentary type. From this study it is possible to state that the "knowledge to teach" and the "knowledge to teach" were present in the official rules for the curricular configuration of undergraduate mathematics courses since the implementation of the first courses. However, the emphasis was primarily on "knowledge to teach", since the insertion of "school mathematics" in official documents took place from 1961, however, without considering the real context of the school. It is in the document published in 2002 that the real need for articulation between this knowledge is made explicit. In this sense, one can affirm the need to understand a new knowledge that is the amalgam between this knowledge.
\end{abstract}

KEYWORDS: Curriculum prescribed. Licensing in Mathematics. Know how to teach. Know to teach.

Conocimiento evidenciado en documentos federales oficiales para el plan de estudios de pregrado de Matemáticas

\title{
RESUMEN
}

El objetivo de investigación presentado en este artículo es comprender el conocimiento explicado en los documentos oficiales, que estandarizan la formación inicial del profesor de Matemáticas. El estudio desarrollado es de naturaleza cualitativa del tipo documental. A partir de este estudio, es posible afirmar que el "conocimiento para enseñar" y el "conocimiento para enseñar" estuvieron presentes en las reglas oficiales para la configuración curricular de los cursos de pregrado en matemáticas desde la implementación de los primeros cursos. Sin embargo, el énfasis estaba principalmente en el "conocimiento para enseñar", ya que la inserción de "matemáticas escolares" en los documentos oficiales tuvo lugar desde 1961, sin considerar el contexto real de la escuela. Es en el documento publicado en 2002 que se hace explícita la necesidad real de articulación entre este conocimiento. En este sentido, uno puede afirmar la necesidad de comprender un nuevo conocimiento que es la amalgama entre este conocimiento. 
PALABRAS CLAVE: Currículum prescrito. Licenciatura en Matemática.

Saber enseñar. Saber enseñar.

$$
* * *
$$

\section{Introdução}

Quando se discute sobre currículo, é importante ressaltar que trata-se de um termo polissêmico, pois é compreendido a partir de diferentes visões pelos pesquisadores. Lopes e Macedo (2011) afirmam haver um enfoque que coincide nas concepções apresentadas por diferentes autores: "a ideia de organização, prévia ou não, de experiências/situações de aprendizagem realizada por docentes/redes de ensino de forma a levar a cabo um processo educativo" (p. 19).

No âmbito do "currículo prescrito e regulamentado" (SACRISTÁN, 1998), foco deste estudo, Liborio e Traldi (2019, no prelo) desenvolveram um estudo exploratório que consistiu na análise de 53 estudos desenvolvidos na área da Educação Matemática e que tiveram como objeto de pesquisa o currículo de cursos de licenciatura em Matemática.

Incialmente, os autores organizaram os estudos em sete categorias de análise: (i) implementação de documentos oficiais e organização curricular (9 trabalhos); (ii) determinado componente curricular e conteúdo (24 trabalhos); (iii) articulação entre currículo da educação básica e da licenciatura em Matemática (2 trabalhos); (iv) intergação das disciplinas especificas com pedagógicas (7 trabalhos); (v) articulação entre teoria e prática (3 trabalhos); (vi) implentação de curso por área de conhecimento e modalidade (3 trabalhos); (vii) currículo dos cursos de formação incial de professores de Matemática em uma perspectiva histórica, a partir de narrativas (5 trabalhos).

A partir do levantamento destes estudos, utilizando-se de procedimentos da Análise de Conteúdo, definido por Bardin (1997), os autores 
constataram que 45, dos 53 trabalhos analisados, tiveram como pressuposto diretrizes curriculares para formarção do professor, publicadas no âmbito federal, para nortear as pesquisas realizadas, tendo estes documentos como norteadores do que era esperado em uma proposta ou prática de cursos de Licenciatura em Matemática. No entanto, sabe-se que os documentos curriculares prescritos, na sua maioria, são traduções de politicas de governo, que nem sempre estão indo na mesma direção dos caminhos promissores revelados pelas pesquisas.

Deste modo, destaca-se a relevância em desenvolver pesquisas que busquem evidenciar saberes ${ }^{3}$ propostos nos documentos curriculares dos cursos de ensino superior, em especial dos cursos de formação inicial de professores de Matemática, ou seja, estudos que consideram o aspecto do "currículo prescrito e regulamentado", que consiste no ordenamento legal, elaborado pelas instâncias políticas e administrativas e tem a função de normatizar e subsidiar a construção dos currículos.

Em todo sistema educativo, como consequência das regulamentações inexoráveis às quais está submetido, levando em conta sua significação social, existe algum tipo de prescrição ou orientação do que deve ser seu conteúdo (...). São aspectos que atuam como referência na ordenação do sistema curricular, servem de ponto de partida para elaboração de materiais, controle do sistema, etc. (SACRISTÁN, 2000, p. 104).

Goodson (1995) também aborda o tema currículo prescrito, afirmando que a sua importância está no fato de que "o currículo escrito nos proporciona um testemunho, uma fonte documental, um mapa do terreno sujeito a modificações; constitui também um dos melhores roteiros oficiais para a estrutura institucionalizada da escolarização" (p. 21).

\footnotetext{
${ }^{3}$ Apesar de concordar com a diferença posta por diferentes autores entre "saber"e "conhecimento", neste artigo o termo "saber" está sendo usado como sinônimo de conhecimento para manter a coerência com o termo utilizado pelos autores que fundamentam a análise.
} 
Nesta perspectiva há autores que investigam os saberes propostos nestes documentos, articulando-os à formação de professores. Hofstetter e Schneuwly (2017), empregam o conceito de "saberes objetivados", que coloca "os saberes formalizados no centro de nossas reflexões, tentando conceitualizar o seu papel nas profissões do ensino e da formação" (p. 131).

De acordo com esses autores, existem "dois tipos constitutivos de saberes", que se referem às profissões da área do ensino e da formação: "os saberes a ensinar, ou seja, os saberes que são os objetos do seu trabalho; e os saberes para ensinar, em outros termos os saberes que são as ferramentas do seu trabalho" (p. 131-132).

Os pesquisadores detalham os "saberes a ensinar", relacionando-os ao campo disciplinar:

O formador-professor forma o outro ensinando saberes; sua função é desse modo constitutivamente definida por saberes aos quais formar os saberes a ensinar (por simplificação, utilizaremos apenas o segundo termo). Estes saberes constituem um objeto essencialmente do seu trabalho. O contrato desse profissional ligando-o à instituição que o emprega define o que deve ensinar, explicitado principalmente por planos de estudos ou currículos, por manuais, dispositivos de formação, textos prescritivos de diferentes tipos. (HOFSTETTER e SCHNEUWLY, 2017, p. 132).

De acordo com os autores, a seleção dos saberes que comporão os "saberes a ensinar", realiza-se por meio de processos "que transformam fundamentalmente os saberes a fim de torná-los ensináveis [...] pode até conduzir à criação de saberes próprios às instituições educativas, necessárias a elas para assumirem suas funções" (p. 133). Deste modo, percebe-se que os "saberes a ensinar" referem-se à conhecimentos remodelados, que são específicos para o trabalho do professor em sala de aula.

No tocante aos "saberes para ensinar", Hofstetter e Schneuwly (2017) afirmam que: 
Formar, como qualquer atividade humana, implica dispor de saberes para sua efetivação, para realizar essa tarefa, esse ofício específico. E esses saberes constituem ferramentas de trabalho, neste caso saberes para formar ou saberes para ensinar (por simplificação utilizaremos aqui também o segundo termo). Tratamse principalmente de saberes sobre "o objeto" do trabalho de ensino e de formação (sobre os saberes a ensinar e sobre o aluno, o adulto, seus conhecimentos, seu desenvolvimento, as maneiras de aprender etc.), sobre as práticas de ensino (métodos, procedimentos, dispositivos, escolha dos saberes a ensinar, modalidades de organização e de gestão) e sobre a instituição que define o seu campo de atividade profissional (planos de estudos, instruções, finalidades, estruturas administrativas e políticas etc.). (p. 133-134).

Esses saberes, mais relacionados ao campo da prática profissional do professor na sua dimensão pedagógica, são essenciais para que se possa exercer a ação docente com maior competência.

Deste modo, temos como objeto de discussão neste estudo investigar os "saberes a ensinar" e os "saberes para ensinar", tendo como objetivo identificar os saberes a ensinar e para ensinar que são explicitados nos documentos oficiais de âmbito federal que normatizam a formação inicial de professores de Matemática, no período de 1925 a 2017.

\section{Desenvolvimento do Estudo}

O estudo desenvolvido consiste em uma abordagem de pesquisa qualitativa, classificando-se como uma pesquisa do tipo documental.

De acordo com Gil (2012),

A pesquisa documental assemelha-se muito à pesquisa bibliográfica. A diferença essencial entre ambas está na natureza das fontes. Enquanto a pesquisa bibliográfica se utiliza 
fundamentalmente das contribuições dos diversos autores sobre determinado assunto, a pesquisa documental vale-se de materiais que não recebem ainda um tratamento analítico, ou que ainda podem ser reelaborados de acordo com os objetos de pesquisa. (p. 4546)

Desta forma, ao realizarmos neste estudo a análise de documentos oficiais de âmbito federal, sejam eles leis, decretos, portarias, resoluções, pareceres e indicações, apesar de compreendermos que tais documentos já tenham recebido "tratamento analítico" (Gil, 2012) por outros pesquisadores, em estudos já desenvolvidos, pretendemos aplicar-lhes tratamentos diferenciados, que atendam aos objetivos deste estudo.

O procedimento adotado para a realização da análise de dados foi a Análise de Conteúdo, que de acordo com Bardin (1977) o seu desenvolvimento ocorre em três fases: pré-análise, exploração do material, e tratamento dos resultados e interpretações.

Essas etapas serão detalhadas, bem como evidenciadas no processo de desenvolvimento desta pesquisa, nas próximas seções.

\section{Pré-análise}

Nesta primeira fase, é realizada uma leitura geral do material coletado, com o objetivo de estabelecer um contato inicial com o tema; seleção do material, visando à definição do corpus de análise; elaboração de indicadores para a compreensão dos dados.

Para a realização desta primeira fase foi feita uma coleta em sites de busca, como Google, Portal de Legislação do Governo Federal4, Portal de Legislações do MEC - Ministério da Educação e publicação institucional do MEC/CFE "Currículos Mínimos dos Cursos de Graduação" (CONSELHO FEDERAL DE EDUCAÇÃO, 1981), com o intuito de identificar quais

\footnotetext{
${ }^{4}$ http://www4.planalto.gov.br/legislacao
} 
documentos oficiais que regulamentam/regulamentaram os cursos de licenciatura no Brasil, em especial os cursos de licenciatura em Matemática, desde 1925 até a contemporaneidade, conforme ilustra o Quadro 1.

Quadro 1 - Agrupamento dos documentos oficiais em períodos históricos

\begin{tabular}{|c|c|}
\hline Período histórico & Documentos Oficiais \\
\hline $\begin{array}{l}\text { A formação do professor } \\
\text { de Matemática: de } 1925 \text { a } \\
1960\end{array}$ & $\begin{array}{l}\text { - Decreto Federal no } 16.782-A \text {, de } 13 \text { de janeiro de } 1925 \\
\text { - Decreto Federal no } 19.851 \text { de } 11 \text { de abril de } 1931 \\
\text { - Decreto Estadual n }{ }^{\circ} 6.283 \text {, de } 25 \text { de janeiro de } 1934 \\
\text { - Decreto-Lei Federal n. } .^{\circ} 1.190 \text {, de } 04 \text { de abril de } 1939 \\
\text { - Decreto-Lei Federal n }{ }^{\circ} 9.053 \text {, de } 12 \text { de março de } 1946\end{array}$ \\
\hline $\begin{array}{l}\text { A formação do professor } \\
\text { de Matemática: de } 1961 \text { a } \\
1995\end{array}$ & 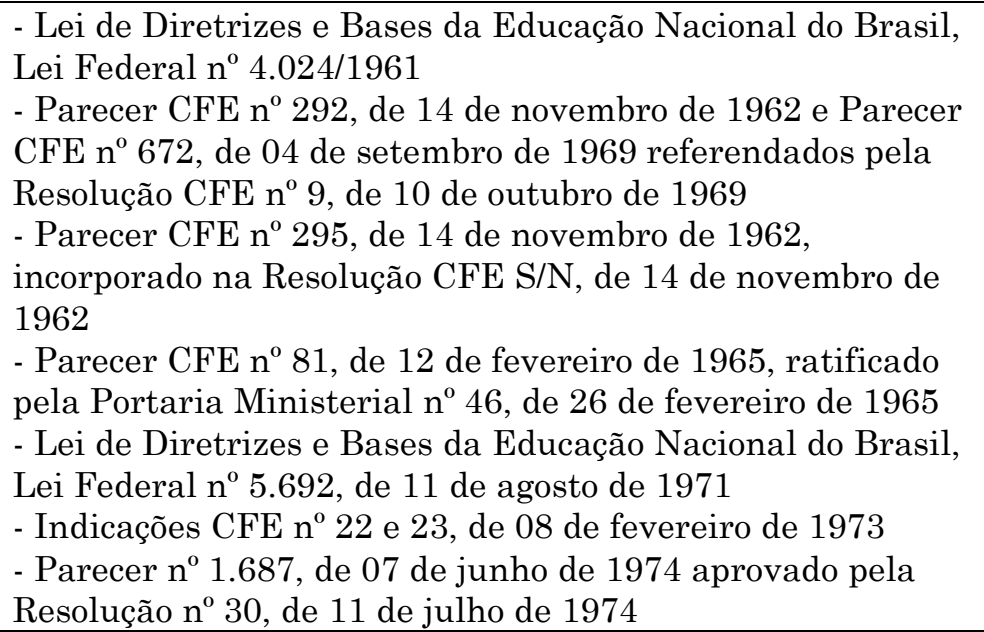 \\
\hline $\begin{array}{l}\text { A formação do professor } \\
\text { de Matemática: a partir de } \\
1996\end{array}$ & $\begin{array}{l}\text { - Lei de Diretrizes e Bases da Educação Nacional do Brasil, } \\
\text { Lei Federal no } 9.394 \text { de } 20 \text { de dezembro de } 1996 \\
\text { - Decreto Federal no } 3.276 \text {, de } 06 \text { de dezembro de } 1999 \\
\text { - Parecer CNE/CP n }{ }^{\circ} 9 \text { de } 08 \text { de maio de } 2001 \text {, aprovado pela } \\
\text { Resolução CNE/CP n } 1 \text {, de } 18 \text { de fevereiro de } 2002 \\
\text { - Parecer CNE/CES no } 1.302 \text {, de } 06 \text { de novembro de } 2001 \text {, } \\
\text { aprovado pela Resolução CNE/CES 3, de } 18 \text { de fevereiro de } \\
2003 \\
\text { - Resolução CNE/CP n }{ }^{\circ} 2 \text {, de } 01 \text { de julho de } 2015 \\
\text { - Lei Federal no } 13.415 \text {, de } 16 \text { de fevereiro de } 2017\end{array}$ \\
\hline
\end{tabular}

Passamos então à leitura dos documentos oficiais selecionados, focando na análise dos conhecimentos explicitados para a formação inicial do professor de Matemática, constituindo assim o corpus de análise deste artigo.

\section{Exploração do material}

Nesta segunda fase foi realizada a codificação dos dados para 
formulação de categorias de análise e organização dos dados em unidades de registro, focando os saberes evidenciados para a formação de professores. Alicerçado nas concepções teóricas defendidas por Hofstetter e Schneuwly (2017) e nos documentos oficiais selecionados, foram formuladas duas categorias de análise, a partir do conceito de "saberes" explicitados para os cursos de formação inicial de professores: os "saberes a ensinar", ou seja, os saberes voltados ao campo disciplinar, que neste estudo são os saberes relacionados à área da Matemática; e os "saberes para ensinar" que são os saberes relacionados à prática do professor, que envolvem metodologias e ferramentas para o exercício de sua prática de professor, saberes pedagógicos.

\section{Análise exploratória dos dados}

A partir dos documentos oficiais selecionados e da análise das características peculiares de cada período histórico, realizou-se um agrupamento destas legislações em três grandes períodos: de 1925 a 1960; de 1961 a 1995 e a partir de 1996.

Justificamos essa organização histórica a fim de auxiliar a realização da análise descritiva e interpretativa dos dados, destacando-se que em 1925 começam a se difundir os cursos superiores no Brasil, levando a criação dos primeiros cursos de Matemática; em 1961, um outro marco temporal surge, com a aprovação da primeira Lei de Diretrizes e Bases da Educação Nacional (Lei $\mathrm{n}^{\circ} 4.024 / 1961$ ), que dispõe sobre novas formas de implementar os cursos de formação inicial de professores, a partir de cursos específicos de licenciatura, somado a outro marco considerado neste estudo, que é a instauração de um regime político militar no Brasil em 1964, que interfere sobremaneira no processo de formação docente e traz ranços até 1995, quando uma nova Lei de Diretrizes e Bases da Educação Nacional (Lei nº 9394/1996) é aprovada, trazendo novas concep̧̧ões de educação e consequentemente alterando as prescrições oficiais para os cursos de formação inicial de professores. 
A seguir serão descritas algumas características, trazidas pelos documentos oficiais supracitados, no tocante ao currículo dos cursos de formação inicial de professores de Matemática, em cada um dos períodos históricos.

\section{A formação do professor de Matemática: de 1925 a 1960}

A partir do Decreto Federal n ${ }^{\circ}$ 16.782-A, de 13 de janeiro de 1925, difunde-se o ensino superior no Brasil, o qual estabelece que os programas de ensino dos cursos de nível superior seriam formulados e aprovados pelas instâncias do próprio estabelecimento de ensino. Pode-se perceber que nesta época não haviam parâmetros para elaboração dos programas curriculares dos cursos e nada era dito, até então, sobre os cursos de licenciatura. Até esta época, quem ministrava as disciplinas escolares para o ensino secundário, eram profissionais formados em cursos de bacharelado.

Uma ampla reforma educacional é implementada por intermédio do Decreto Federal n 19.851 de 11 de abril de 1931, também denominado por "Estatuto das Universidades Brasileiras" ou "Reforma Francisco Campos", trata-se do primeiro Ministro da Educação, que exercia o cargo à época da aprovação desta normativa.

Gomes (2016) destaca que uma das justificativas do governo federal para a implementação da referida reforma do ensino superior em 1932, está pautada principalmente pelo

[...] caráter urgente atribuído à necessidade de prover uma formação profissional para os professores, em especial os do ensino secundário. A Faculdade de Educação, Ciências e Letras prevista no Decreto $\mathrm{n}^{0}$ 19.850, de 11 de abril de 1931, deveria ser, além de um "órgão de alta cultura ou de ciência pura e desinteressada", sobretudo, um "Instituto de Educação", dotado de "todos os elementos próprios e indispensáveis a formar o nosso corpo de professores, particularmente os do ensino normal e secundário", 
porque deles, de modo próximo e imediato, dependeria "a possibilidade de se desenvolver, em extensão e profundidade, o organismo, ainda rudimentar, de nossa cultura". O texto criticava a cultura autodidática dos professores dominante no país e enfatizava a ideia de que faltava ao ensino secundário brasileiro um corpo docente "de orientação didática segura e com sólidos fundamentos em uma tradição de cultura, particularmente no que se refere às ciências básicas e fundamentais" (p. 426)

Identifica-se uma preocupação do governo federal em promover a formação de professores qualificados para atuarem no ensino secundário, por meio da criação de cursos específicos que possibilitassem uma formação integral para a atuação profissional no magistério. Reconhece que há a necessidade dos "saberes para ensinar" na formação do professor, que deve estar presente na sua formação incial.

Em 1934 é criada a Universidade de São Paulo (USP), atendendo aos preceitos da "Reforma Francisco Campos", mas com alguns distanciamentos. A USP institui, dentre outros cursos, o de "Ciências Matemáticas", vinculado à "Secção de Ciências" da "Faculdade de Filosofia, Ciências e Letras". Este curso tinha como finalidade formar o bacharel e o licenciado em matemática e, referente às cadeiras fundamentais do curso, apresenta-se:

I - Ciências Matemáticas: Geometria (projetiva e analítica); História das Matemáticas; Análise matemática (inclusive elementos de cálculo das probabilidades e de estatística matemática); Cálculo Vetorial e Elementos de Geometria Infinitesimal. Mecânica Racional e Elemento de Mecânica Celeste. (SÃO PAULO, 1934)

Percebe-se que a parte em comum de formar os licenciados e bacharéis se distância da "matemática escolar" e privilegia a "matemática acadêmica" (MOREIRA e DAVID, 2010), já que os saberes relacionados ao campo disciplinar da formação do professor é constituído pelos acadêmicos, não 
considerando saberes produzidos no contexto escolar.

O referido Decreto estabelece ainda a concessão da "licença para o magistério secundário" ao candidato concluinte dos cursos da "Faculdade de Filosofia, Ciências e Letras”, por meio da realização de um curso de formação pedagógica, simultaneamente ao terceiro ano do curso de referência, oferecido no "Instituto de Educação". A "Secção de Matérias de Ensino", destinada aos que desejassem a referida licença para o magistério no ensino secundário, organizava-se da seguinte maneira:

Constituirá uma seç̧ão autônoma da de prática de ensino e terá por fim o estudo teórico-prático: a) da metodologia da matéria, das dificuldades que lhe são inerentes, e das técnicas e processos para remove-las; b) da importância da matéria para formação mental do adolescente; c) da história do ensino da matéria; d) da correlação de cada matéria com as demais; e) dos princípios e da prática da organização dos programas escolares. (SÃO PAULO, 1934).

Cabe salientar que as disciplinas da "Secção de Matérias de Ensino" eram realizadas em espaços diferentes de onde realizava-se o curso de "Ciências Matemática", havendo assim um distanciamento dessas formações, favorecendo a dicotomia entre o "saber a ensinar"e o "saber para ensinar". Outro aspecto relevante a ser considerado, é que os conteúdos da "Secção de Matérias de Ensino" estavam concentrados no período de um ano, realizado simultaneamente ao terceiro ano do curso de referência, podendo assim ter o entendimento de que após o aluno dominar os conteúdos específicos da disciplina de referência, a sua formação seria acrescida com a aprendizagem de conteúdos pedagógicos e ao final ele estaria apto para exercer a docência.

Já ao que se refere aos conteúdos abordados na "Secção de Matérias de Ensino", destaca-se a indicação de estudos "teórico-prático" referente à "metodologia da matéria, das dificuldades que lhe são inerentes, e das técnicas e processos para remove-las" (SÃO PAULO, 1934), que está relacionado aos "saberes para ensinar" (HOFSTETTER e SCHNEUWLY, 
2017), no entanto percebe-se que, apesar de presente no documento, estes saberes não eram tratados considerando as especificidades da disciplina, visto que estavam alocados no Instituto de Educação. Vale ressaltar que no documento de 1939 aparece pela primeira vez uma disciplina com a proposta de abordar os conteúdos matemáticos na perspectiva do ensino "Didática especial”.

Este modelo de formação de professores secundários ${ }^{5}$ no Brasil ficou conhecido como " $3+1$ ", em que os discentes cursavam 3 (três) anos de formação específica e mais 01 (um) ano de formação pedagógica, reforçando a dicotomia entre tais formações. Neste modelo de formação, é possível compreender que a alteração mais significativa, em relação ao formato anterior (1934) referese aos "saberes para ensinar", em que o "curso de formação pedagógica" é substituído pelo "curso de Didática", sendo que no modelo de 1934, os conhecimentos estão diretamente relacionados à matéria a ser ensinada, já no modelo de 1939, são incorporados outros conhecimentos voltados para a formação generalista do professor, como: psicologia educacional e fundamentos biológicos e sociológicos da educação. A "matemática acadêmica" permanece de forma hegemônica no currículo destes cursos, não havendo elementos substancias que tratem da aproximação com a escola secundária, com foco nas suas necessidades formativas.

Sobre este período, apesar de suas limitações, destaca-se a implantação das primeiras experiências de cursos de formação de nível superior em Matemática no Brasil, que de certa forma permitiu o crescimento deste campo disciplinar, mediante as pesquisas desenvolvidas pelas universidades e possibilitando ainda uma mudança acerca da concepção de profissional que ministraria essa disciplina, antes lecionada exclusivamente por militares e engenheiros. Também é possível afirmar que nos documentos oficiais os "saberes a ensinar" tinham um espaço privilegiado em termos de carga

\footnotetext{
${ }^{5}$ Professor Secundário - Ministrava aulas para o nível secundário de educação, compreendendo os Cursos Ginasial, o que corresponde hoje ao Ensino Fundamental $-6^{\circ}$ ao $9^{\circ}$ Ano e Colegial (Clássico ou Científico), que corresponde hoje ao Ensino Médio. (BRASIL, 1942).
} 
horária e permanência no decorrer do curso ao comparar com os "saberes para ensinar".

\section{A formação do professor de Matemática: de 1961 a 1995}

A partir da Lei de Diretrizes e Bases da Educação Nacional do Brasil, Lei Federal $n^{0} 4.024 / 1961$, as instituições de ensino superior passam a ter uma diretriz de âmbito federal a ser seguida no processo de elaboração do currículo dos cursos de ensino superior:

Art. 70. O currículo mínimo e a duração dos cursos que habilitem à obtenção de diploma capaz de assegurar privilégios para o exercício da profissão liberal ... VETADO ... serão fixados pelo Conselho Federal de Educação. (BRASIL, 1961)

Observa-se a instauração de uma padronização nos currículos dos curos de licenciatura, já que os cursos de todo o país deveriam cumprir um currículo mínimo definido pelo Conselho Federal de Educação. Pode-se afirmar que este currículo mínimo passou a ser o currículo dos cursos.

Com o intuito de regulamentar o artigo 70 da Lei Federal n ${ }^{\circ} 4.024 / 1961$, o Parecer CFE n ${ }^{\circ}$ 292, de 14 de novembro de 1962 e ainda o Parecer CFE n ${ }^{\circ}$ 672, de 04 de setembro de 1969 referendados pela Resolução CFE nº 9, de 10 de outubro de 1969, preveem os currículos mínimos dos cursos de licenciatura para o magistério de $2^{\circ}$ grau ${ }^{6}$, abrangendo as seguintes matérias pedagógicas:

Psicologia da Educação (focalizando pelo menos os aspectos da

Adolescência e Aprendizagem); Didática; Estrutura e Funcionamento do Ensino de $2^{\circ}$ Grau (CONSELHO FEDERAL DE EDUCAÇÃO, 1981, p. 37)

\footnotetext{
${ }^{6} 2^{\circ}$ grau - Corresponde hoje ao Ensino Médio.
} 
Além disso, a Resolução CFE nº 9/1969, determina a obrigatoriedade da Prática de Ensino por meio de estágio supervisionado, a ser desenvolvido "em situação real, de preferência em escola da comunidade" (CONSELHO FEDERAL DE EDUCAÇÃO, 1981, p. 37).

Destaca-se que tal prescrição oficial, evolui em relação à normativa anterior (Decreto-Lei Federal n ${ }^{\circ}$ 9.053/1946), visto que a prática dos docentes em formação deixa de acontecer de forma opcional no âmbito dos "Ginásios de Aplicação", passando a ser realizada de forma obrigatória em "Escolas da Comunidade", sendo evidenciado pelo Relator Conselheiro Valnir Chagas no Parecer CFE n⿳0 292/1962:

Para trazer o necessário realismo àquelas abordagens mais ou menos teóricas da atividade docente. É de estranhar que até agora, entre as exigências oficiais para a formação do magistério, ainda não figurasse a Prática de Ensino com o merecido relevo. [...] não se concebe que uma intervenção cirúrgica [...] esteja a cargo de médico que a faça pela primeira vez e, paradoxalmente, se entrega a educação de uma criança ou de um jovem, ato que tem repercussões para toda a vida, a professores que jamais se defrontaram antes com um aluno. (CONSELHO FEDERAL DE EDUCAÇÃO, 1981, p. 34)

Verifica-se nesta perspectiva, uma preocupação dos legisladores em promover uma maior aproximação entre as universidades e a cultura escolar.

Cabe destacar que a "formação pedagógica" proposta no modelo anterior (até 1960), estava pautada pelo modelo $3+1$, sendo desenvolvida ao final do terceiro ano do curso de formação específica por meio dos "cursos de formação pedagógica” ou “curso de didática”. Já no modelo proposto em 1962, essa formação deveria estar diluída ao longo da trajetória de formação do estudante, de forma paralela à formação das disciplinas específicas, entretanto com a recomendação de compor o mínimo de um oitavo (1/8) da carga-horária total do curso, sendo que este percentual correspondia à metade do que era aplicado no modelo anterior, que aplicava um quarto (1/4) em 
disciplinas de formação pedagógica.

O Parecer CFE $n^{0} 295$, de 14 de novembro de 1962, incorporado na Resolução CFE S/N, de 14 de novembro de 1962, estabelece o seu currículo mínimo, compreendendo as seguintes matérias:

1. Desenho Geométrico e Geometria Descritiva; Fundamentos de Matemática Elementar; Física Geral; Cálculo Diferencial e Integral; Geometria Analítica; Álgebra; Cálculo Numérico; Matérias pedagógicas, de acordo com o Parecer $\mathrm{n}^{0}$ 292/62. (CONSELHO FEDERAL DE EDUCAÇÃO, 1981, p. 547-548)

Destaca-se que a matéria "Fundamentos de Matemática Elementar" consistia em uma:

[...] análise e revisão dos assuntos lecionados nos cursos de Matemática dos ginásios e dos colégios não só tendo em vista dar aos licenciados um conhecimento mais aprofundado desses assuntos como ainda para procurar enquadrá-los no conjunto das teorias matemáticas estudadas pelo aluno. (CONSELHO FEDERAL DE EDUCAÇÃO, 1981, p. 547)

A referida disciplina compreendia em uma síntese e revisão dos conteúdos matemáticos já estudados pelo aluno no ensino secundário, com o único objetivo de aprofundar os conhecimentos matemáticos para o desenvolvimento do aprendizado de novas teorias matemáticas.

Cabe salientar que os "saberes a ensinar" presentes na formação inicial específica do professor de Matemática, neste período, ainda se encontra pautado por uma "matemática acadêmica", não havendo uma visão voltada para o saber matemático escolar.

No tocante à inclusão obrigatória da "Prática de Ensino por meio de estágio supervisionado" nos cursos de licenciatura, observa-se que os "saberes a ensinar" nestes cursos não sofrem transformações, já que não se evidenciam 
nos textos legais recomendações no sentido de promover a reflexão da prática desenvolvida, resumindo-se à reprodução no ambiente escolar dos conhecimentos e técnicas aprendidos durante o curso universitário.

Cabe salientar que a ênfase neste período, recai no aspecto quantitativo em detrimento do qualitativo, já que a preocupação maior estava em formar professores de forma aligeirada e que abarcasse um número significativo de disciplinas, de modo a suprir a falta de professores.

Com o fim do Regime Militar em 1985, o Brasil entra no período conhecido como "Redemocratização", sendo que este modelo de formação de professores perdurou no Brasil até ao final dos anos 1990, quando passou a vigorar as novas legislações que passamos a expor a seguir.

\section{A formação do professor de Matemática: a partir de 1996}

Em 1996 é aprovada a terceira e atual Lei de Diretrizes e Bases da Educação Nacional do Brasil, Lei Federal nº 9.394 de 20 de dezembro de 1996, que, no âmbito do currículo dos cursos superiores, transfere maior autonomia às universidades, ao estabelecer que são asseguradas a elas próprias a organização do currículo dos seus cursos, inclusive das licenciaturas, observadas as diretrizes gerais, a serem editadas pelo Conselho Nacional de Educação, que servirão de parâmetro para elaboração dos programas dos cursos.

O Decreto Federal $\mathrm{n}^{\circ}$ 3.276, de 06 de dezembro de 1999, que regulamenta o artigo 62 da LDB, versa sobre a formação do professor para atuação na educação básica, e estabelece que compete ao Conselho Nacional de Educação definir as Diretrizes Curriculares Nacionais para a formação de professores da educação básica. Desta forma, em 2002, por meio do Parecer $\mathrm{CNE} / \mathrm{CP}$ n $^{\circ} 9$ de 08 de maio de 2001, aprovado pela Resolução CNE/CP n ${ }^{0} 1$, de 18 de Fevereiro de 2002, é instituída as Diretrizes Curriculares Nacionais para a Formação de Professores da Educação Básica. Segundo Schneider (2007), essas Diretrizes 
[...] estabelecem princípios orientadores amplos, diretrizes para a formação de professores e critérios para a organização da matriz curricular sem, no entanto, explicitar conteúdos. Por não oferecerem caminhos fechados, elas são consideradas um avanço em relação a propostas anteriores, consubstanciadas pela acepção de Estado Autoritário, que fixava currículos mínimos. (p. 13)

O referido documento oficial, apresenta alguns aspectos que devem permear a organização curricular dos cursos de formação inicial para a atividade docente, dentre os quais destacamos, o preparo para

I - o ensino visando à aprendizagem do aluno; o acolhimento e o trato da diversidade; [...] a elaboração e a execução de projetos de desenvolvimento dos conteúdos curriculares; VI - o uso de tecnologias da informação e da comunicação e de metodologias, estratégias e materiais de apoio inovadores (BRASIL, 2002)

Apresentam-se ainda, princípios norteadores que devem estar presentes nos cursos de formação, como: o trato da competência como conceito central no decorrer do curso, a correlação entre a formação universitária e a futura prática profissional, sendo destacado o conceito de "simetria invertida", em que a preparação do professor, pelo fato de realizar-se em local semelhante ao que vai atuar profissionalmente, demanda coerência entre as práticas desenvolvidas no curso de formação e o que se espera deste futuro docente. Acerca deste conceito, o Parecer CNE/CP n ${ }^{\circ}$ 9/2001, aponta para o processo formativo docente

[...] a necessidade de que o futuro professor experiencie, como aluno, durante todo o processo de formação, as atitudes, modelos didáticos, capacidades e modos de organização que se pretende venham a ser concretizados nas suas práticas pedagógicas. (BRASIL, 2001, p. 30- 
Nesta perspectiva, compreende-se que a formação da identidade profissional do docente é contínua, está relacionada à toda sua trajetória escolar, desde os anos iniciais do Ensino Fundamental, passando pelo Ensino Médio, Graduação, Pós-Graduação, sem haver uma terminalidade, pois em seu percurso profissional, por meio do processo de educação continuada, as suas práticas profissionais podem sempre ser reinventadas.

Tal documento estabelece ainda que a seleção de conteúdos deve ser conduzida de forma a abordar conhecimentos que vá além daquilo que os professores irão lecionar na educação básica, devendo ser tratados de modo articulado com a didática específica.

Alguns conhecimentos mais amplos também devem ser tratados como:

I - cultura geral e profissional; II - conhecimentos sobre crianças, adolescentes, jovens e adultos, aí incluídas as especificidades dos alunos com necessidades educacionais especiais $\mathrm{e}$ as das comunidades indígenas; III - conhecimento sobre dimensão cultural, social, política e econômica da educação; IV - conteúdos das áreas de conhecimento que serão objeto de ensino; V - conhecimento pedagógico; VI - conhecimento advindo da experiência. (BRASIL, 2002)

Destaca-se que o tempo destinado aos aspectos pedagógicos, deve contemplar o mínimo de $20 \%$ da carga horária total do curso, evidenciando que a parte prática nos cursos de formação de professores não deve limitar-se aos momentos de estágio, perpassando a formação do professor desde o início do curso: "No interior das áreas ou das disciplinas que constituírem os componentes curriculares de formação, e não apenas nas disciplinas pedagógicas, todas terão a sua dimensão prática”. (BRASIL, 2002). Ainda, é destacado a necessidade de construção de uma visão global dos conteúdos e que sejam significativos para o aluno. É indicada uma relação de conteúdos que devem ser comuns em todos os cursos de licenciatura em Matemática, 
sendo eles:

Cálculo Diferencial e Integral; Álgebra Linear; Fundamentos de Análise; Fundamentos de Álgebra; Fundamentos de Geometria; Geometria Analítica. A parte comum deve ainda incluir: a) conteúdos matemáticos presentes na educação básica nas áreas de Álgebra, Geometria e Análise; b) conteúdos de áreas afins à Matemática, que são fontes originadoras de problemas e campos de aplicação de suas teorias; c) conteúdos da Ciência da Educação, da História e Filosofia das Ciências e da Matemática. (BRASIL, 2001, p. 6).

Em 2015, as novas Diretrizes Curriculares Nacionais para a formação inicial de Professores são instituídas por meio da Resolução CNE/CP no 2, de 01 de julho de 2015, revogando a DCN anterior. Os principais pontos trazidos por esta legislação são: possibilidade dos cursos de licenciaturas serem organizados por componente curricular ou por campo de conhecimento e/ou interdisciplinar; garantia da articulação entre a teoria e prática ao longo do curso; estabelecimento de que os currículos das licenciaturas devem conter:

[...] conteúdos específicos da respectiva área de conhecimento ou interdisciplinares, seus fundamentos e metodologias, bem como conteúdos relacionados aos fundamentos da educação, formação na área de políticas públicas e gestão da educação, seus fundamentos e metodologias, direitos humanos, diversidades étnico-racial, de gênero, sexual, religiosa, de faixa geracional, Língua Brasileira de Sinais (Libras), educação especial e direitos educacionais de adolescentes e jovens em cumprimento de medidas socioeducativas. (BRASIL, 2015, p. 11).

A LDB n ${ }^{\circ}$ 9.394/1996 passou por atualização em 2017, incluindo ao seu texto a Lei Federal $n^{0} 13.415$, de 16 de fevereiro de 2017, que determina que os cursos de formação de professores terão por referência a Base Nacional 
Comum Curricular 7.

Em síntese é possível compreender, no que se refere aos "saberes a ensinar", que a LDB n ${ }^{\circ}$ 9.394/1996 transfere autonomia às universidades para a organização curricular dos seus cursos, devendo observar algumas diretrizes gerais emanadas do Conselho Nacional de Educação, como as Diretrizes Curriculares Nacionais para a formação de professores da educação básica (2002; 2015), os Parâmetros Curriculares Nacionais (1997), as Diretrizes Curriculares Nacionais da Educação Básica (2010) e mais recentemente a Base Nacional Comum Curricular (2017).

Ainda, em relação aos "saberes a ensinar", é possível identificar-se uma maior ênfase nos saberes da "matemática escolar" presentes nas orientações oficiais para os cursos de formação inicial de professores, já que é apresentada uma relação de conteúdos comuns aos cursos de licenciatura em Matemática, destacando-se os "conteúdos matemáticos presentes na educação básica nas áreas de Álgebra, Geometria e Análise" (BRASIL, 2001) e mais recentemente a necessidade de os cursos de formação de professores terem por referência a Base Nacional Comum Curricular. Nesta perspectiva, a Matemática a ser ensinada vai ao encontro das concepções de Moreira e David (2010), que defendem a necessidade da incorporação de saberes matemáticos relacionados ao contexto educativo nos cursos de formação de professores.

Em relação aos "saberes para ensinar" identificou-se uma maior presença dos saberes sobre "o objeto" do trabalho do futuro professor relacionados aos processos de ensino e de aprendizagem, diferentes metodologias de ensino e a compreensão de diferentes maneiras de aprender Matemática, além de temas ligados à diversidade cultural, social, étnicoracial, de gênero, necessidades educacionais especiais; direitos humanos; o conhecimento sobre as crianças, jovens e adultos.

\footnotetext{
${ }^{7}$ A Base Nacional Comum Curricular (BNCC) é um documento de caráter normativo que define o conjunto orgânico e progressivo de aprendizagens essenciais que todos os alunos devem desenvolver ao longo das etapas e modalidades da Educação Básica. Disponível em: http://basenacionalcomum.mec.gov.br/
} 


\section{Considerações}

Pode-se concluir que os "saberes a ensinar" e os "saberes para ensinar" estiveram presentes nas normativas oficiais para a configuração curricular dos cursos de licenciatura em Matemática desde a implantação dos primeiros cursos. Porém, a ênfase, até os documentos publicados na década de 1996, estava prioritamente nos "saberes a ensinar". No entanto, o "saber a ensinar" é definido a partir dos saberes acadêmicos, que não necessariamente são os saberes escolares. A partir dos documentos publicados entre 1961 a 1995, os legisladores começam a se preocupar com a inserção de elementos da "matemática escolar" nos documentos oficiais que normatizam o currículo dos cursos de licenciatura em Matemática, com a inclusão de conteúdos matemáticos julgados relevantes para a prática profissional do professor de Matemática, a seleção de conteúdos que se relacionem com o que vai ser ensinado na educação básica, entretanto ainda sem considerar o contexto real da escola.

Em relação ao "saber para ensinar", que aparece como uma preocupação explicita no Decreto de 1925, quando estabele a necessidade de programas para formar professores do ensino secundário, e que possibilita a implementação da Reforma de 1932, em que está pautada na necessidade de prover formação profissional ao professor do ensino secundário, propondo a criação dos "Instituos de Educação", possibilita a a organização dos cursos com uma prioridade muito díspar entre a carga horária dos "saberes a ensinar", que passam a ocupar aproximadamente $75 \%$ destes cursos, em relação a carga horária das disciplinas que comporiam os "saberes para ensinar", que eram de $25 \%$. Além disto, até a publicação da Diretrizes para Formação de Professores, em 2002, estes conhecimentos eram tratados de forma desarticulada.

É no documento publicado em 2002 que é explicitado a real necessidade da articulação entre o "saber a ensinar" e o "saber para ensinar". Porém, ainda é posto como um desafio aos cursos de formação de professores esta 
articulação, pois para que ela exista deve-se constituir um novo saber que é o amálgama entre o "saber a ensinar" e o "saber para ensinar", e que caracterizará o saber profissional do professor de Matemática.

\section{Referências}

BARDIN, L. Análise de conteúdo. Lisboa: Edições 70, 1977.

BRASIL. Lei $n^{\circ}$ 4.024, de 20 de dezembro de 1961. Fixa as Diretrizes e Bases da Educação Nacional. Disponível em: http://www.planalto.gov.br/ccivil_03/leis/L4024.htm. Acesso em: 02 mar 2018.

BRASIL. Lei $n^{\circ}$ 9.394, de 20 de dezembro de 1996. Estabelece as diretrizes e bases da educação nacional. Disponível em: http://www.planalto.gov.br/ccivil_03/LEIS/19394.htm. Acesso em: 02 mar 2018.

BRASIL. Lei $n^{\circ} 13.415$, de 16 de fevereiro de 2017. Altera a Lei n. 9.394, de 20 de dezembro de 1996, que estabelece as diretrizes e bases da educação nacional. Disponível em: http://www.planalto.gov.br/ccivil_03/_ato20152018/2017/lei/l13415.htm. Acesso em: 02 mar 2018.

BRASIL. Conselho Nacional de Educação. Parecer $C N E / C P n^{\circ}$ 9/2001, de 08 de maio de 2001. Diretrizes Curriculares Nacionais para a Formação de Professores da Educação Básica, em nível Superior, curso de licenciatura, de graduação Plena. Disponível em: $<$ http://portal.mec.gov.br/index.php?option=com_content\&view=article\&id=12636\& Itemid=86>. Acesso em: 02 mar 2018.

BRASIL. Resolução CNE/CP 01/2002, de 18 de fevereiro de 2002. Diretrizes Curriculares Nacionais para a Formação de Professores da Educação Básica, em nível superior, em cursos de licenciatura de graduação plena. Disponível em: $<$ http://portal.mec.gov.br/index.php?option=com_content\&view=article\&id=12633\& Itemid=86>. Acesso em: 02 mar 2018.

BRASIL. Parecer CNE/CES 1.302/2001, de 06 de novembro de 2001. Diretrizes curriculares nacionais para os cursos de matemática, bacharelado e licenciatura. Disponível em: <http://portal.mec.gov.br/cne/arquivos/pdf/CES13022.pdf > . Acesso em: 02 mar 2018.

BRASIL. Resolução CNE /CP n ${ }^{\circ}$ 2/2015, de 01 de julho de 2015. Define as Diretrizes Curriculares Nacionais para a formação inicial em nível superior (cursos de licenciatura, cursos de formação pedagógica para graduados e cursos de segunda licenciatura) e para a formação continuada. Disponível em: $<$ http://portal.mec.gov.br/docman/agosto-2017-pdf/70431-res-cne-cp-002-03072015pdf/file>. Acesso em: 02 mar 2018. 
BRASIL. Secretaria de Educação Fundamental. Parâmetros curriculares nacionais. Brasília: MEC/SEF, 1997.

CONSELHO FEDERAL DE EDUCAÇÃO. Currículos mínimos dos cursos de graduação. 4. ed. Brasília, 1981.

GIL, A. C. Métodos e técnicas de pesquisa social. 6 ed. 5. reimpr. São Paulo: Atlas, 2012.

GOMES, M. L. M. Os 80 anos do primeiro curso de Matemática brasileiro: sentidos possíveis de uma comemoração acerca da formação de professores no Brasil. Bolema. Rio Claro, v. 30, n. 55, p. 424-438, 2016.

GOODSON, I. F. Currículo: teoria e história. Petrópolis: Vozes,1995.

HOFSTETTER, R.; SCHNEUWLY, B. Saberes: um tema central para as profissões do ensino e da formação. In: HOFSTETTER, R.; VALENTE, W. R. (orgs.) Saberes em (trans)formação: tema central da formação de professores. São Paulo: Livraria da Física, 2017.

LIBORIO, R. G. C.; TRALDI Jr, A. Estudo exploratório de pesquisas relacionadas ao tema currículo de cursos de licenciatura em matemática. Educação Matemática Pesquisa, 2019. No prelo.

LOPES, A. C.; MACEDO, E. Teorias de Currículo. São Paulo: Cortez, 2011.

MOREIRA, P. C.; DAVID, M. M. M. S. A Formação Matemática do Professor: licenciatura e prática docente escolar. Belo Horizonte: Autêntica, 2010.

SACRISTÁN, J. G. O currículo: uma reflexão sobre a prática. Porto Alegre: Artmed, 2000 .

SÃO PAULO. Decreto $\mathrm{n}^{\circ}$ 6.283, de 25 de janeiro de 1934. Cria a Universidade de São Paulo dá outras providências. Disponível em: https://www.al.sp.gov.br/norma/130436. Acesso em: 02 mar 2018.

SCHNEIDER, M. P. Diretrizes Curriculares Nacionais para a Formação de Professores da Educação Básica: das determinações legais às práticas institucionalizadas. Tese de Doutorado. Universidade Federal de Santa Catarina UFSC. 2007. Disponível em: < https://core.ac.uk/download/pdf/30371634.pdf> Acesso em: 28 nov 2018.

Recebido em outubro de 2019.

Aprovado em novembro de 2019. 